\title{
DIVISON XI
}

\section{SPACE AND HIGH ENERGY ASTROPHYSICS}

Division XI connects astronomers using space techniques or particle detectors for an extremely large range of investigations, from in-situ studies of bodies in the solar system to orbiting observatories studying the Universe in wavelengths ranging from radio waves to gamma rays, to underground detectors for cosmic neutrino radiation.

PRESIDENT

G Srinivasan

RRI

Sadashivanagar

CV Raman Av

Bangalore 560080

India

Tel: $+91-803340122$

Fax: $+91-803340492$

Email:srini@rri.ernet.in

BOARD
M. Arnaud
S. Baliunas
S. Bludman

Th.-J.L. Courvoisier

J.M. da Costa Past President Commission 37

H. Hasan

G. Hasinger

P.T. O'Brien

L. Piro

R. Schilizzi

B. Shustov

W. Wamsteker

Past President Division XI

Wang Zhenru

\section{PARTICIPATING COMMISSION}

COMMISSION 44:

SPACE AND HIGH ENERGY ASTROPHYSICS 


\section{DIVISION XI : SPACE AND HIGH ENERGY ASTROPHYSICS (ASTROPHYSIQUE SPATIALE ET DES HAUTES ENERGIES)}

\section{PRESIDENT: Willem Wamsteker}

BOARD: S. Baliunas, N. Brosch, C. Cesarsky, Th.-J.L. Courvoisier, J.M. da Costa, V. Domingo, C. Fransson, A. Fabian, G. Fazio, G. Hasinger, H. Inoe, Li Zhongyuan, P.T. O'Brien, H. Okuda, H. Quintana, T.N. Rangarajan, R. Schilizzi, B. Shustov, H. Thronson, O. Vilhu, Wang Zhenru

Commission 44: Space and High Energy Astrophysics

\section{Introduction}

Two business meetings of Division XI/Commission 44 were held, associated with th XXIVth General Assembly of the IAU in Manchester, United Kingdom, on Wednesday 9 August 2000 (before the opening of the IAU GA) and on 11 August 2000. Chair of the meetings was Dr. W. Wamsteker, President of the Division; the President of Commission 44 Prof. G. Srinivasan was also present.

\section{Report of the President}

During the reporting period (1997-2000) all activities for Commission 44 were coordinated in the context of the Division. Two of the Division's members -previous officers of the original Commission 48: Space- have been honored by COSPAR for their contributions to Space Astrophysics: Prof. R.M. Bonnet was awarded the COSPAR Space Science Award and Prof. S. Bowyer was awarded the Massey Award. During the past triennium the Division has kept the members of the IAU appraised of the status of observatories in Space through the News from the Division section in the IAU Bulletin.

Associated with the XXIVth General Assembly of the IAU the Division co-sponsored the following Symposia:

- Symposium 202. Planetary Systems in the Universe.

- Symposium 203. Recent Insights into the Physics of the Sun and Heliosphere: Highlights from $\mathrm{SOHO}$

It supported or co-sponsored the following Joint Discussions:

- JD 1. Atomic and Molecular Data for Astrophysics: New Developments, Case Studies and Future Needs

- JD 7. The Sun and Space Weather

- JD 10. Cluster Mergers and their Connection to Radio Sources

- JD 11. First Results for the FUSE Mission 
And it organized two special scientific sessions:

Division XI (Science Session):

1. "New X-Ray Missions". (12 August)

During this session the performance characteristics of the new X-Ray missions CHANDRA and XMM-NEWTON were extensively discussed and their first science results presented. The meeting also served as good forum for the scientists involved in both missions, to exchange experiences between the two projects in an informal environment.

Jointly between Division XI and Working Group for Future Large Scale Facilities (Science Session):

2. "Future Observational Multi-Wavelength Capabilities in Astrophysics."(10 August) This session was used to present a more long-term outlook of the future of observational astrophysics with a multi-wavelength angle. Many exiting projects were presented and a common thread was identified, in that a stronger global cooperation will be needed in the future to maintain the dynamics of observational astronomy. The meeting was concluded with a formal Memorandum of Understanding signature ceremony by 10 Countries, formalizing the International Steering Committee for Square Kilometer Array (SKA). This ceremony was attended by the General Secretary of the IAU.

For 2001 the Commission has agreed to co-sponsor the IAU Symposium 209: Planetary Nebulae: Their Evolution and Role in the Universe. The World Wide Web page at http://www.vilspa.esa.es/IAU-XI/ was maintained.

\section{Working Groups}

The Division has one Working Group: Astronomy from the Moon. The current WG chairman, Prof. Y. Terzian requested to be relieved from this responsibility and proposed Prof. N. Kaifu to succeed him. Prof. Kaifu was willing to accept this task and the nomination was approved. The Working Group held one meeting in coordination with Division X (Radio Astronomy). A consideration from Division $\mathrm{X}$ was to re-establish the Working Group under Division $X$ rather than its curtent home under Division XI. This was motivated by the perception that, at this moment, considerable attention is directed to the fact that the backside of the Moon could be an important site for Radio Astronomy in the future. It was however generally felt that, as any facilities on the Moon would unavoidably involve the Space Agencies and the Moon could also be beneficial to other observational techniques, it would be unwise to effect the transfer.

Chairman Working Group for Astronomy from the Moon: Prof. N. Kaifu

Two new Working Groups were proposed to be created in Division XI:

- Working Group on Particle Astrophysics Goals: The need for the creation of a Working Group for Particle Astrophysics was presented to be the fact that this field represents the last major observational barrier for Astrophysics. As the width of the area to be addressed by this Working Group was rather extended (from Gravitational Waves to Cosmic Rays), it was considered to be most appropriate to have the members of the WG to clarify in detail the issues which should be the field of activity of the Working Group. The members will submit their detailed views to the Board of Directors of the Division for approval. Chairman Working Group on Particle Astrophysics : TBD. 
- Working Group on World Space Observatories (WSO) Goals: The Division perceived the need for creation of a Working Group for World Space Observatories (WSO). This would evaluate the problems and possibilities concerning open access for the International Scientific Community to future Observatories in Space. The long preparation time associated with Space Observatories, the uncertainties in sustained funding levels for such projects -often solely driven by technology needs-imply that WSO's could possibly contribute very much to Space Astronomy, in the professional level as well as in the raising of conscience of the general population. The importance of Basic Space Science in the development of pre-industrial economies in the world was also noticed to represent an important issue.

After discussion and consultation with the Executive Committee it was decided that such issues really belonged in the WGFLSF, and it was agreed that a Divisional representative would become member of the WGFLSF (Dr. W. Wamsteker as of August 2000). The issues suggested to be addressed by the proposed WG will be addressed in the context of WGFLSF and will be reported.

\section{Officers 2000-2003}

Following the By-Laws and Working Rules of the IAU, an early consultation was held by E-mail within the Board of the Division to present new Officers to the Division Business Meeting and to the Executive Committee. Such early consultation was necessary since it was required to bring the number of members in the Board within the limits established in the By-Laws. This required to bring the number of members back to one half. To do this and to fulfill, at the same time the needs for renovation and continuity, presented some difficulties. Also the agreements between Commission 44 and 48 made in the IAU XXIIIrd $\mathrm{GA}$, on the merge of the two Commissions, foresaw the elimination of Commission 44 this year (Commission 48 (Space) had already been eliminated in the XXXIIrd IAU GA business meetings). As this had been the basis for the consultation, a proposal was presented to the Business meeting consistent with this history. Some members voiced concerns related to the agreements apparently made in the past with the EC. After consultation, the EC requested not to suppress Commission 44 , as it was felt that there were clearly two communities within the Division XI structure. These would be better served if the Commission identity was retained. Also the EC considered that the Presidency of the Division should be on alternative triennia be selected from either the Space, or the High Energy community. The consideration being that the Vice-President would represent the alternate community. To accommodate the perceived needs of the EC, a compromise proposal was submitted to the EC for the officers of the Division and the Commission. This was rejected by the EC, and the EC decided it was necessary to reappoint the President of Commission 48 for another 3 years. As the President of the Division was required to be the same, the Board of the Division is now as follows:

G. Srinivasan (President)

H. Okuda (Vice-President)

Officers: S. Baliunas, P.T. O'Brien, M. Arnaud, B. Shustov, Th.-J.L. Courvoisier, G. Hasinger, L. Piro, J.M. da Costa, R. Schilizzi, Wang Zhenru, H. Hasan, W. Wamsteker S. Bludman.

As the current arrangements seem somewhat ad hoc, and are rather impractical for the future (it would require to maintain a field qualification associated with the members which has no formal basis), it is recommended that for the next Business meeting of Division XI, a clear position is prepared and discussed, which will be effective and is consistent with the By-Laws and Working Rules of the IAU.

Willem Wamsteker

President of the Division 